THE $11^{\text {TH }}$ EDITION OF

The International Congress of Automotive and Transport Engineering

MOBILITY ENGINEERING AND ENVIRONMENT

November 8-10, 2017

\title{
Compression tests methods on car engines
}

\author{
M F Toma ${ }^{1 *}$, D A Micu ${ }^{1}$, C N Andreescu ${ }^{1}$ and C Iota ${ }^{2}$ \\ ${ }^{1}$ Automotive Engineering Department, University POLITEHNICA of Bucharest, \\ Splaiul Independentei, Nr. 313, Romania \\ ${ }^{2}$ S.C. Robert Bosch S.R.L. Romania Str. Horia Macelariu nr. 30-34, 013937 \\ Bucharest, Romania \\ *Corresponding author e-mail: marius.toma@upb.ro \\ $\begin{array}{rr}\text { Article history } & \\ \text { Received } & 10.06 .2017 \\ \text { Accepted } & 23.09 .2017\end{array}$ \\ DOI https://doi.org/10.26825/bup.ar.2017.010
}

\begin{abstract}
Correct operation of the internal combustion engine requires the best possible seal of the combustion chamber during the period when the valves are closed. A perfect seal of the combustion chamber can not be achieved because of the constructional features of the segments as well as the play between the piston and the cylinder. In time, the wear of moving parts leads to a continuous worsening of the seal. Different complexity and accuracy methods are used to measure the combustion chamber's leakage. In this article, the following methods of measuring the engine cylinder leakage are presented: measuring the pressure in the cylinder at the end of the compression process using a compression gauge, measuring the current drawn by the starter motor, comparing engine speeds when the engine is cranked over by the starter and comparing engine speeds on idle. The paper presents the comparative analysis of the values obtained by different methods with the cold engine compared to the hot engine and a comparative analysis between the results obtained by using the different methods of measuring the engine cylinder leakage. The paper demonstrates that measuring the pressure using a compression gauge is the most accurate method for determining the leakage of the combustion chamber.
\end{abstract}

\section{Introduction}

A correct operation of the internal combustion engine requires the best possible seal of the combustion chamber during the period when the valves are closed. The way this goal is achieved influences the development of thermal processes, having direct repercussions on the engine's 
energy and economic performance, higher fuel and engine oil consumption, lower cold start capacity, faster engine oil degradation as well as its behavior regarding its environmental pollution [1].

The level of combustion chamber sealing depends on the technical state of the following engine components: piston - piston rings - cylinder, valve - valve seat, cylinder head and cylinder head gasket. Measuring the engine cylinder leakage may be an indirect way of evaluation of the technical condition of these parts with no need to disassemble the engine.

A perfect seal of the combustion chamber can not be achieved because of the constructional features of the piston rings as well as the play between the piston and the cylinder. Using the engine, the wear of moving parts leads to a continuous worsening of the seal. Also, the leakage of the combustion chamber may also be compromised as a result of accidental causes: breaking or blocking of the piston rings, damage to the cylinder head gasket, valve blocking, pinching of the valve stem edges and / or valve seats, failure of the cylinder head on the common surface with the cylinder block, cracking the walls of the combustion chamber in the cylinder head, or incorrect setting of the clearance of the distribution mechanism at too low values [2]. Differences of values prove that not only the tightness of engine combustion chamber but also the changes of its technical condition and correctness of regulation [3].

To measure the combustion chamber's leakage, different complexity and accuracy methods are used. This article presents the following methods:

a) Quantitative methods: measuring the pressure in the cylinder at the end of the compression process using a compression gauge;

b) Qualitative methods:

- measuring the current drawn by the starter motor;

- comparing engine speeds when the engine is cranked over by the starter;

- comparing engine speeds on idle.

\section{Objective}

The research is carried out on a compression ignition engine with the following objectives:

a) Comparative analysis of the results obtained using different methods;

b) Comparative analysis of the values obtained with the cold engine compared to the hot engine if the same method is applied;

c) Establishing a correlation between different methods to determine the sealing of the combustion chamber.

\section{Preparing and conducting the experimental investigation}

The paper refers to the measurement of the engine cylinder leakage by four quantitative and qualitative methods.

The tests were carried out on a 2008 Opel Astra $\mathrm{H}$ equipped with compression ignition engine with Z19DT engine code, $1910 \mathrm{~cm}^{3}$ capacity and compression ratio of 18.4 [4].

Before the tests procedures, specific preparatory operations were carried out according to the measurement method. The battery charge level has been checked and the proper operation of the diesel fuel system has been checked.

\subsection{Measuring the pressure in the cylinder at the end of the compression process using a compression gauge}

This method involves measuring the pressure at the end of the compression process using a special compression gauge for diesel engine, while the engine is started by the electric motor.

In [4] and [5] it is recommended that the measurement should be done with hot engine (coolant temperature higher than $80^{\circ} \mathrm{C}$ ). Measurement of compression can be done by replacing incandescent plugs or injectors with special compression gauge adapters. For technical reasons, it has been chosen to measure it by removing the injectors. All four diesel injectors are removed after the engine has been warmed up, in accordance with the procedure indicated in [5]. The highpressure pump has to be disabled. The special adapter is mounted instead of the injector and the compression pressure is measured. 
For each cylinder, five measurements were made. Measurements have been made so that the tests run as soon as possible and the engine temperature drop during the measurements is reduced.

The compression pressure was determined (figure 1) first with the cold engine $\left(20^{\circ} \mathrm{C}\right.$ coolant temperature) and then with the hot engine, using the Diesel Motometer compression gauge.

According to [4] and [6], for Opel Z19DT engine in hot condition (coolant temperature higher than $80^{\circ} \mathrm{C}$ ), the pressure at the end of the compression process must be between 24 bar and 32 bar.

\subsection{Measuring the current drawn by the starter motor during cranking}

The principle underlying this method is that a current of specific intensity is absorbed during the compression process is taking place in each cylinder: the better the tightness of the combustion chamber, the more the resistances of the piston displacement in the compression process from the cylinder Respectively, are higher and implicitly the intensity of the current absorbed by the starter in the starting process will be higher. In [7], the worse tightness decreases the values of instantaneous current during the leaking cylinder's compression stroke comparing to the faultless cylinder. The measurement results in [8] confirm strong relationship between the tightness of the combustion chamber of engine and current of the starter.

The measurements were made with the Bosch FSA 740 diagnostic unit from UPB, the Automotive Engineering Department. Figure 1 shows the interface where the result of a measurement is displayed.

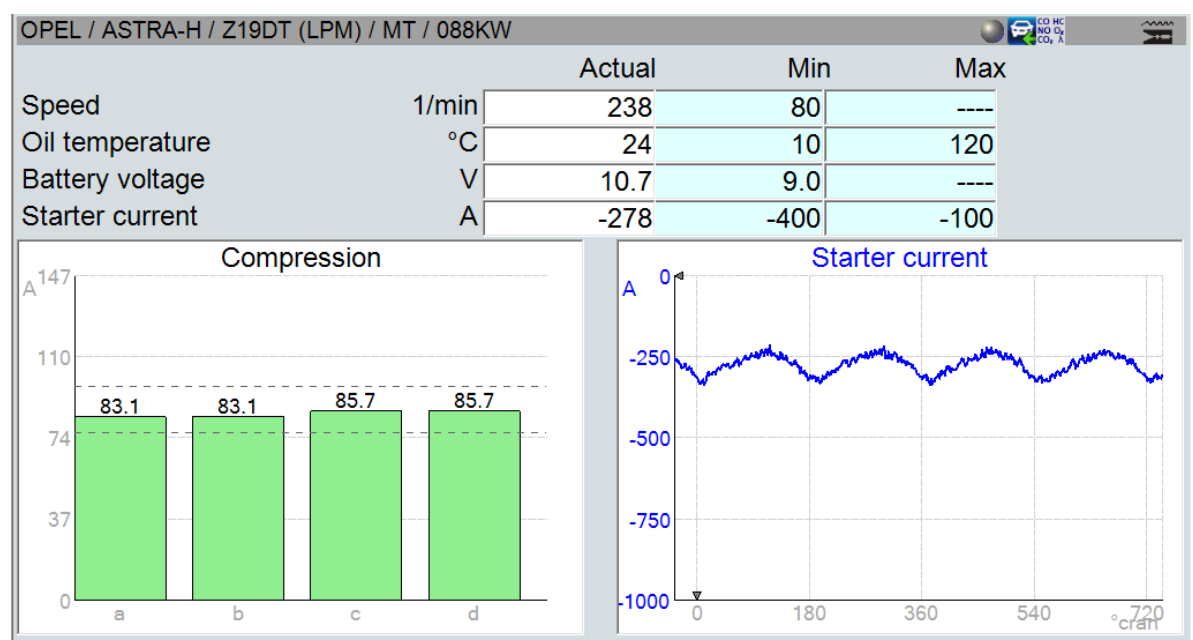

Figure 1. Measuring the current drawn by the starter motor during cranking.

At the end of the measurement, the following measured parameters are displayed: speed, oil temperature, battery voltage in the start-up process, and the average value of the absorbed starting current, corresponding to a complete cycle. It also shows graphically the values of the currents required to overcome the resistance of each cylinder (left) and the variation of the current absorbed by the starter (right) during one cycle. The left histograms represent the differences between the minimum values of the absorbed current required for cranking and the values measured during the compression processes.

The cylinders "a, b, c, d" does not correspond to the engine cylinder positions. They respect the ignition sequence of the engine "1-3-4-2", but cylinder "a" is the one at which the first compression was recorded from the moment the contact was actuated. Thus, this method can not determine the location of possible leaks, but only their existence.

Figure 1 shows also the allowable range in which the absorbed current has to be located for proper leakage. This range depends on the vehicle, the engine, the test range (motor temperature) and the current value of the absorbed current. The higher the current, the higher the admissible range. For example, in figure 1, the admissible range is between $76 \mathrm{~A}$ and $97 \mathrm{~A}$.

\subsection{Comparing the engine speeds in the last part of the compression stroke of each cylinder when cranking}


The test is based on analysis of the angular velocity values obtained from the engine speed transducer. The engine speed is displayed for each cylinder, for the last part of the compression stroke, in the starting mode by the starter - figure 2. The principle of the method is as follows: the better the tightness, the higher the resistance to the actuation of the motor mechanism and the speed corresponding to the cylinder is smaller.

Diagnosis is done using the Bosch KTS 570. It is connected to the car's OBD interface and the specific software is used. The test is done both with cold and hot engine. The results of this test show the speed values of each piston during the crankshaft driven by the starter, figure 2 .

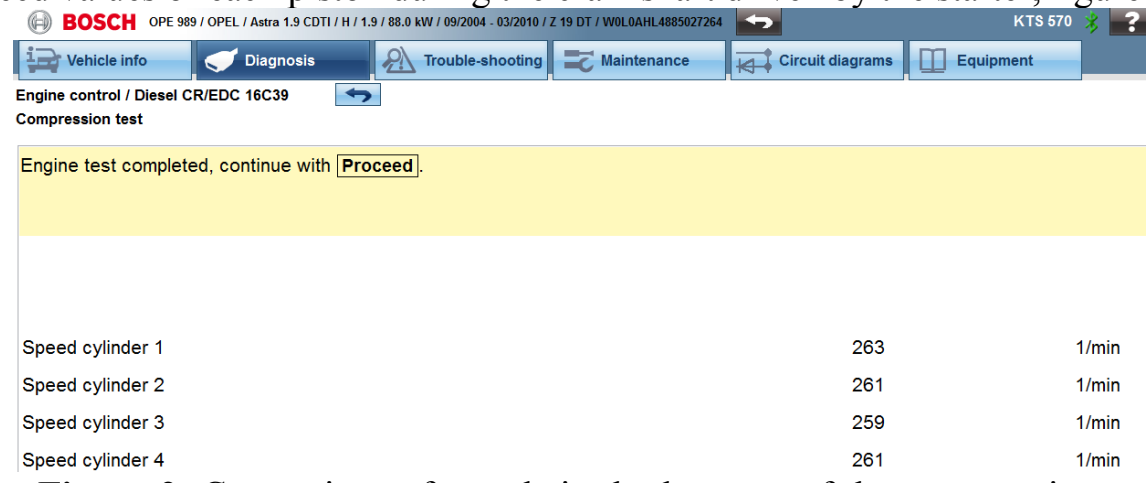

Figure 2. Comparison of speeds in the last part of the compression stroke of each cylinder when cranking.

According to [6], a difference of maximum $7 \mathrm{~min}^{-1}$ between any two values measured on the four cylinders is considered acceptable.

\subsection{Comparing the engine speeds at the beginning of the expansion process of each cylinder when idling}

The test is based on the analysis of the information received from the engine speed transducer when idling. The Engine Control Unit (ECU) sets an identical injection time for all injectors for a certain speed and load regime. The engine speed at the beginning of the expansion process is measured and displayed for each cylinder, as shown in figure 3. The principle of the method is as follows: the better the sealing is, the higher the gas pressure and the higher the engine speed of the cylinder.

Since the speeds are influenced by the injection quality and by the double-flywheel, this principle is only applicable once it is known that the ignition, supply and distribution system are in good working condition. Diagnosis is done using the Bosch KTS 570. It is connected to the car's OBD interface and specific software is used.

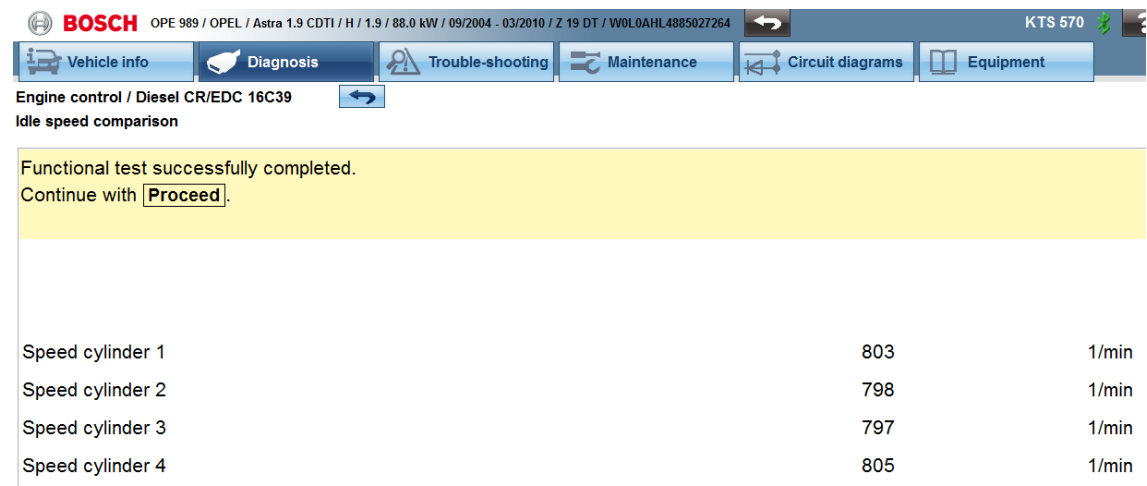

Figure 3. Comparison of engine speeds at the beginning of the expansion process of each cylinder when idling.

According to [6], a difference between the maximum and minimum speed measured on the four cylinders of $21 \mathrm{~min}^{-1}$ is considered permissible. 


\section{Results and their interpretation}

\subsection{The pressure at the end of the compression process}

Following the tests, the cold and hot engine pressure values are shown in figure 4.

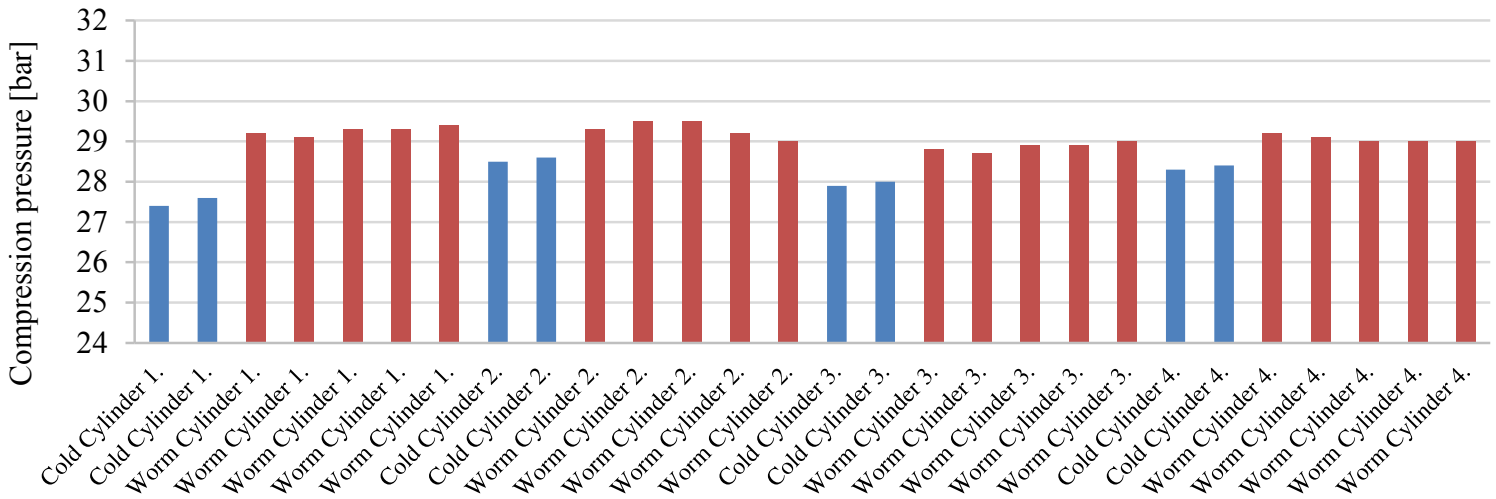

Cylinder and its condition

Figure 4. The pressure at the end of the compression process.

The compression pressure measured is within the tolerable range of $24 \div 32$ bar in both thermal measurement modes. The average values of the cold engine measured pressures are lower than the average values of the pressures measured with the hot engine by $3 \%$ to $6 \%$. In the paper [5] it is said that these differences between cold and hot values are around $10 \%$. Great differences occur because "cold engine" expression is relative, depending on the ambient temperature.

All five measurements for each cylinder have very close values. In their order from 1 to 4 , cylinders degrees of non-uniformity are: $1 \%, 1.7 \%, 1 \%$ and $0.7 \%$.

The third cylinder has the smallest pressure, with an average of 28.9 bar. Cylinders one and two have the highest average values of compression pressure of 29.3 bar. The degree of non-uniformity of the average values measured on all cylinders is $1.4 \%$, below the maximum admissible limit of 2 $\div 4 \%$, indicated in paper [2]. The compression pressure values measured according to [4] show that the engine is properly leakproof.

\subsection{Results obtained when measuring the current drawn by the starter motor during cranking}

For measuring the current drawn by the starter motor, five sets measurements of cold engine (engine oil temperature $24^{\circ} \mathrm{C}$ ) and five sets measurements of hot engine $\left(80^{\circ} \mathrm{C}\right.$ oil temperature) were made. The results are shown in figure 5. The intensities of the current drawn by the starter during cranking each cylinder are shown for each set of measurements. The order of graphical representation of the cylinder intensities is different at each measurement since the first result will correspond to the cylinder at which the first compression was recorded from the moment the starter was actuated.

In figure 5, the order of graphical representation corresponds to the order of the measurements. Intensity values measured with the cold engine are higher by $41 \%$ on average than the average measured currents with the hot engine.

The average value of the cranking engine speed is 244 min- 1 and ranges from 216 min- 1 to 258 min-1. As the engine is cold, play from cinematic couplings is bigger, but the lubrication is deficient. The higher density of the oil increase the resistance of the mechanisms. This explains the high values of current measured at cold tests. The first measurement was made after a 24-hour immobilisation of the car. It was observed that the first recorded values were the highest and after that, they were stabilized. The non-uniformity of the cold measured values was between $3.1 \div$ $6.5 \%$, below the $10 \%$ limit recommended in the paper [4].

The sets of measured values with hot engine have a non-uniformity of $4.4 \%$ (sets 1, 2, 4 and 5) and for set three is $8.3 \%$. Four of the five sets of measurements are identical as shown in figure 5. It is known that the third cylinder has the lowest leak-tightness (4.1). The method of measuring the 
current drawn by the starter when starting the engine confirms this value. Given the order of ignition, it is pointed out that there is the same cylinder that absorbs the smallest current.

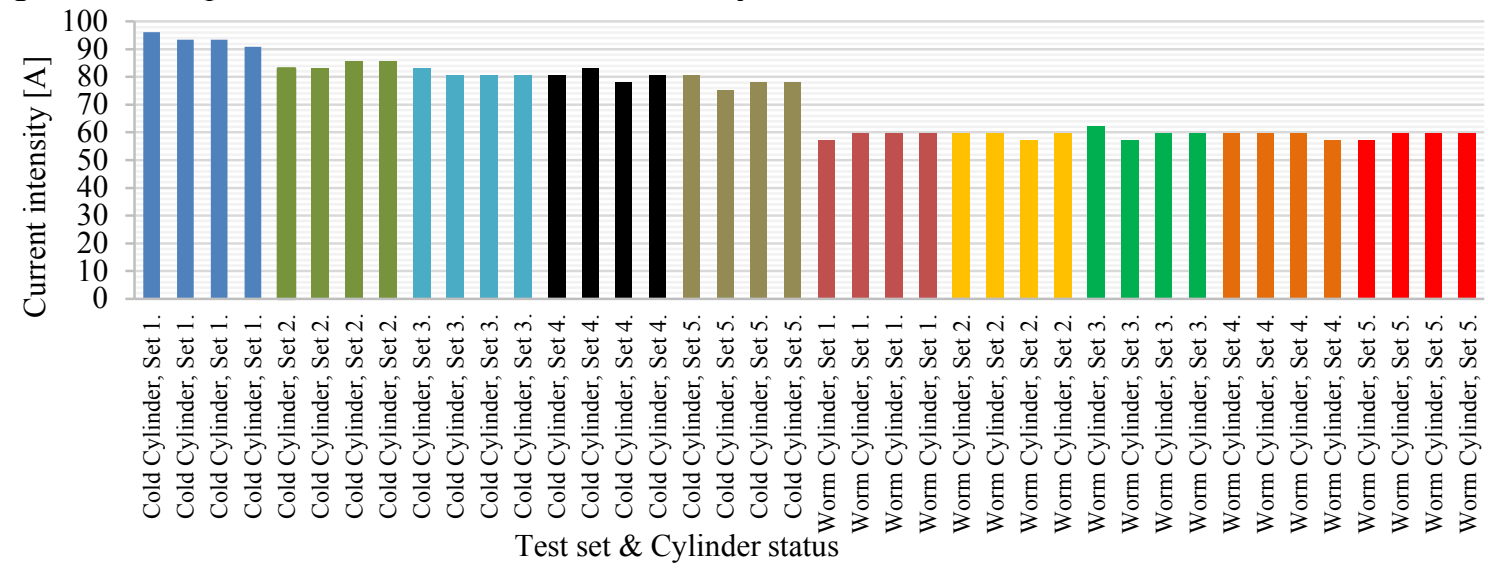

Figure 5. The current drawn by the starter motor during cranking.

Although valuable information is obtained during the cold test, it is recommended that this type of measurement be made with the warm engine for better accuracy of the results. The method presented is very useful in measuring the tightness of the combustion chamber because it is very fast and requires few preparatory operations.

\subsection{Results obtained when comparing the engine speeds in the last part of the compression stroke of each cylinder during cranking}

For each cylinder speed, five measurements sets of cold engine (engine oil temperature $26^{\circ} \mathrm{C}$ ) and five measurements sets of hot engine (oil temperature in the range $87 \div 90^{\circ} \mathrm{C}$ ) were made. Individual engine speeds corresponding to each cylinder are displayed for each measurement set, as it is shown in figure 6 .

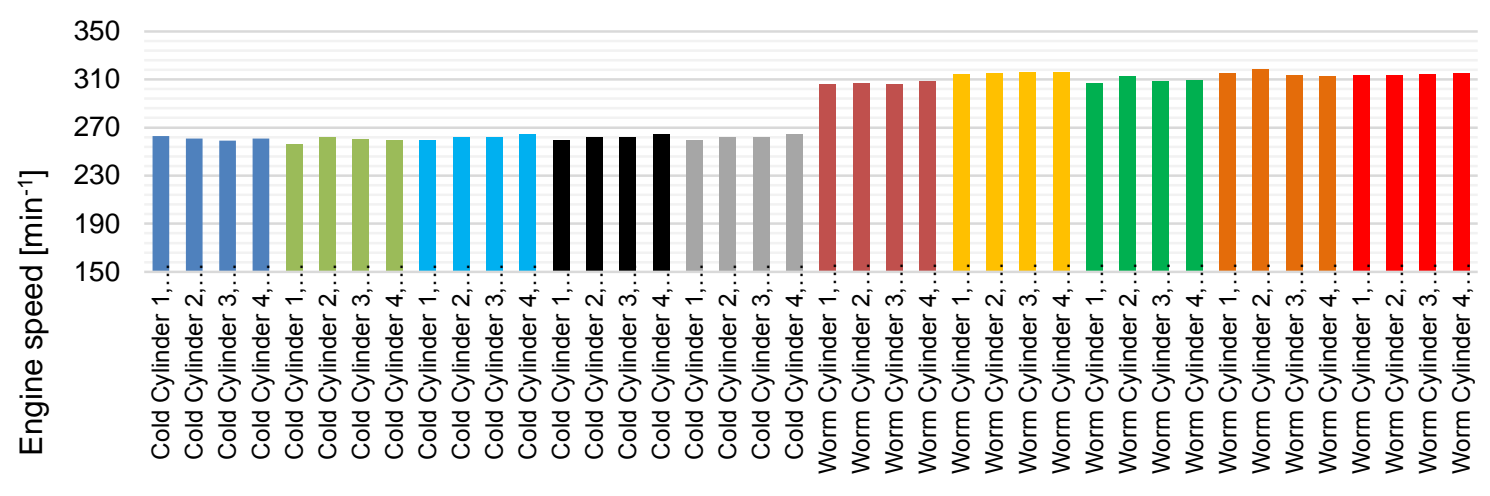

Test set \& Cylinder status

Figure 6. Engine speeds in the last part of the compression stroke of each cylinder during cranking.

The engine speeds are lower by an average of $16 \%$ when the engine is cold than when the engine is hot. This is due to the above mentioned causes in section 4.2. On average, at cold measurements, the engine speed of the starter is $261 \mathrm{~min}-1$ and varies between $256 \div 264 \mathrm{~min}-1$, which is $1.5 \div 2.3 \%$ below the $10 \%$ recommended in the [4].

Analyzing the results obtained with hot and cold engine, it is found that in both situations, the cylinder one has the lowest speed. That means the best sealing is shown for cylinder one in four of the five sets of tests. For cylinder one and two, the average pressure values measured with the compression gauge (4.1) were the highest.

Although relevant information is obtained during the cold test, the unevenness of the measured values is relatively high. Consequently, for better accuracy of results, it is recommended that this 
type of measurement to be done with warm engine. The method presented is very useful in measuring the tightness of the combustion chamber because it is quick and requires little preparatory work.

\subsection{Results obtained when comparing the engine speeds at the beginning of the expansion process} of each cylinder when idling

To measure the engine speeds when idling, five measurements sets of cold $\left(\mathrm{t}_{\mathrm{oil}}=50^{\circ} \mathrm{C}\right)$ and hot $\left(\mathrm{t}_{\mathrm{oil}}\right.$ $=80^{\circ} \mathrm{C}$ ) engine were made. The results are shown in figure 7 . The engine speeds corresponding to each cylinder are displayed for each set of measurements.

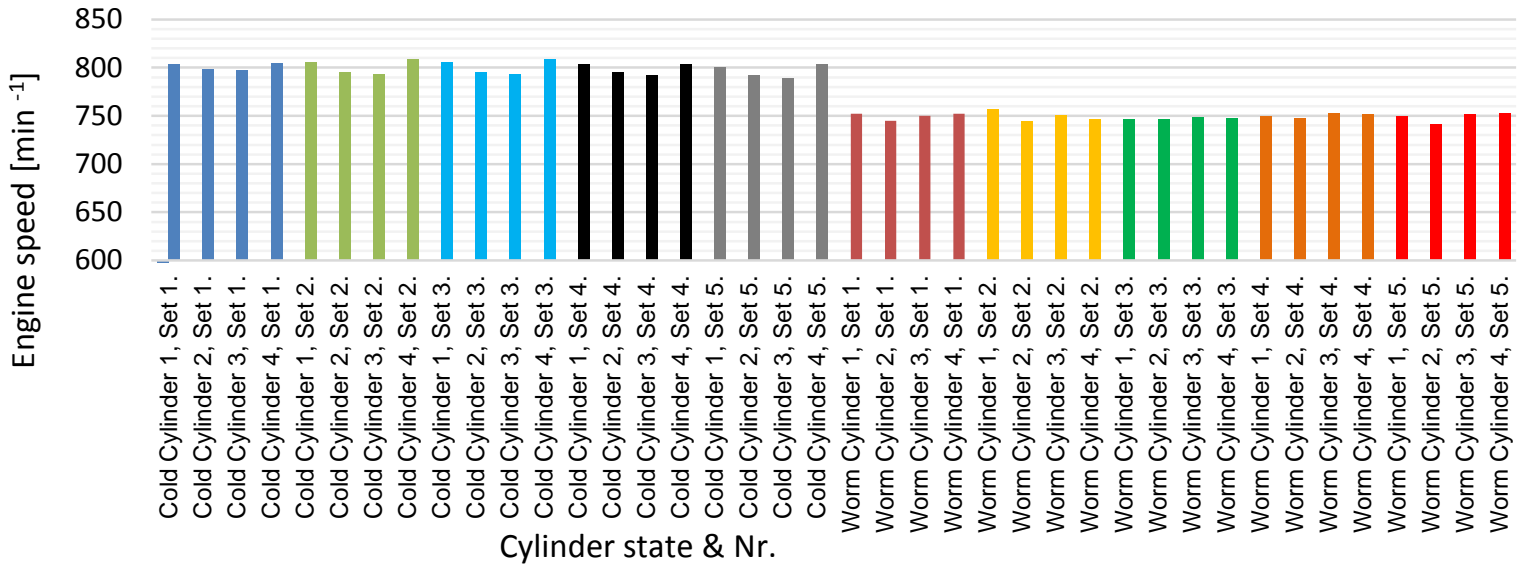

Figure 7. Engine speeds at the beginning of the expansion process of each cylinder when idling.

When idling, the engine speed decreases as the engine warm up. On cold start, the engine has a higher engine speed for a steady ride. Then, the engine speed is dropped and stabilized as it gets warm. Values depend on many factors including ambient temperature.

The engine speeds are lower on average by $6.3 \%$ when they are measured on cold than they are measured on hot engine. For cold measurements, the idling speed slowly varies between $793 \div 809$ $\mathrm{min}^{-1}$ with an average value of $800 \mathrm{~min}^{-1}$. The non-uniformity of the cold measured values was between $1 \div 2 \%$ below the $10 \%$ limit recommended in the paper [4].

With hot engine, the average value of idling speed is $750 \mathrm{~min}^{-1}$ and ranges from 741 to $757 \mathrm{~min}^{-}$ 1. The non-uniformity of the measured values was between $0.4 \div 1.6 \%$.

Analyzing the results obtained with cold engine, it is found that, in all five sets of tests, the third cylinder corresponds to its lowest speed, so it has the lowest tightness. The same result was achieved by measuring the pressure with the compression gauge. This method indicates that the fourth cylinder has the best tightness, but this is not confirmed by the pressure measurement using compression gauge. When interpreting these results, it is important to consider that the engine speed is changed after the cold start until it is stabilized. An important factor is the working temperature of cylinders. It is known that the middle cylinders warm up faster than the exterior cylinders, so their corresponding speed will decrease faster (will be stabilized faster).

Figure 7 shows that at all five sets of measurements made with cold engine the lowest speed was measured on cylinders 3 and 2 which warm up faster. This explains why the test program requires the measurement to be done with the warm engine.

\section{Conclusions}

Measuring the pressure by using the compression gauge is the most reliable method because it is a quantitative method. This method requires the disassembly of some components of the diesel fuel system. The measurements are relevant for both hot and cold engines. The five measured values for each cylinder have very close values. The degree of non-uniformity of the measurement sets for each cylinder varies between $0.7 \%$ and $1.7 \%$.

The cylinders with the best tightness are cylinders 1 and 2. Cylinder 3 has the lowest tightness.

By measuring the current drawn by the starter motor during cranking, it is determined whether the tightness is good or not. The method is a qualitative one. Although valuable information is 
obtained during the cold test, it is recommended that this type of measurement be made with warm engine for better accuracy of the results. The method is very useful in measuring the tightness of the combustion chamber because it is very fast and requires few preparatory operations.

Comparing the engine speeds in the last part of the compression stroke of each cylinder when cranking is an indirect but very useful method in assessing the tightness of the combustion chamber because it is fast and requires few preparatory operations.

Comparing the engine speeds at the beginning of the expansion process of each cylinder when idling Is a rapid, indirect method for determining the sealing of the combustion chamber. The measured values are influenced by the fuel injection quality, the state of the ignition system and the dual mass flywheel.

These last two methods are convenient when using a complex diagnosis system which is able to perform a wide range of tests concerning several engine devices: injectors, transducers, EGR system, injection timing etc.

The method of measuring the current drawn by the starter during cranking shows that the value of cylinder 3 has the weakest tightness. The pressure measured by using the compression gauge shows the same.

Analyzing the results obtained when comparing the engine speeds in the last part of the compression stroke of each cylinder during cranking it was found that the cylinder 1 has the smallest leakage. Cylinders 1 and 2 presented the highest mean values of compression pressure.

The results obtained comparing the engine speeds when idling confirm that the third cylinder had the lowest tightness. The same result was achieved by measuring the pressure with the compression gauge. This method indicates that the fourth cylinder has the best tightness, but this is not confirmed by the pressure measurement using compression gauge. When interpreting these results, it is important to consider that the engine speed is changed after the cold start until it is stabilized.

The first three methods of measuring the combustion chamber's tightness have shown very close results using different measurement principles. This conclusion recommends the use of alternative (qualitative) methods of measuring the compression of the combustion chamber because they are fast and reliable without requiring costly preparatory actions.

\section{References}

[1] Koszałka G 2014 Model of operational changes in the combustion chamber tightness of a diesel engine Eksploatacja i Niezawodnosc - Maintenance and Reliability 16 pp 133-139

[2] Andreescu C, Oprean I M, Danciu G and Anghelache G 2002 Diagnosticarea Automobilelor - Lucrari Practice (Bucuresti: Editura Printech) pp 50-59

[3] Roslanowski J and Charchalis A 2013 Evaluation accuracy of combustion chamber tightness in piston engines, on the basis of a developed indicator diagram, J. of KONES Powertrain and Transport $20 \mathrm{pp} 339-345$

[4] Andreescu C, Anghelache G and Toma M 2011 Mentenanța Mijloacelor de Transport (București: Editura Acedemiei oamenilor de Știință din România) pp 75-79

[5] 2008 Manual de întreținere și reparare Opel Astra H

[6] 2008 Bosch ESI[tronic], documentație tehnică Opel Astra H

[7] Pošta J, Kadleček B and Hladík T 2003 Engine combustion chamber tightness diagnostics, RES. AGR. ENG. 492003 pp 115-118

[8] Jukl M, Polcar A and Čupera J 2014 Possibilities of monitoring the technical condition of the combustion engine with starter load current, Acta Univ. Agric. Silvic. Mendelianae Brun. 62 pp 961-969 (Preprint https://doi.org/10.11118/actaun201462050961) 